\title{
AVALIAÇÃO DA PRECISÃO EXPERIMENTAL DE UM EXPERIMENTO DE MILHO EM CONSÓRCIO COM FEIJÃO PARA A PRODUÇÃO DE MILHO VERDE E SECO
}

\author{
Islan Diego Espindula de Carvalho ${ }^{1}$, Paulo Vanderlei Ferreira², José Pedro da Silva ${ }^{3}$, Thalyson Vasconcelos de \\ Lima $^{4}$, Carla Caroline Alves Pereira ${ }^{5}$, Patricia da Silva Santos ${ }^{6}$ \\ 'Mestrado pela Universidade Federal de Alagoas, iislandiego@hotmail.com, \\ 2Professor da Universidade Federal de Alagoas; \\ ${ }^{3}$ Professor do Instituto Federal de Alagoas, Campus Murici; \\ ${ }^{4}$ Mestrando da Universidade Federal Rural de Pernambuco; \\ ${ }^{5}$ Mestrado pela Universidade Federal Rural de Pernambuco; \\ ${ }^{6}$ Graduanda em Engenharia Agronômica da Universidade Federal de Alagoas. \\ Autor para correspondência: Patricia da Silva Santos, p.fera.pp@gmail.com
}

\begin{abstract}
RESUMO: O milho é uma das culturas agrícolas de maior importância econômica e social, pois é cultivada por pequenos e grandes produtores. Os pequenos produtores em sua maioria utilizam o sistema de consórcio em sua produção, por isso, diversos experimentos dessa natureza têm sido realizados. Esse tipo de experimento, devido sua natureza heterogênea apresenta sempre coeficiente de variação elevado. Para verificar a precisão experimental, muitos pesquisadores estão utilizando outros parâmetros estatísticos, como o teste $\mathrm{F}$, Tukey, acurácia, entre outros. Esse trabalho teve como objetivo avaliar a precisão experimental de um experimento de milho em consórcio com feijão para a produção de milho verde e seco. Foram utilizados nesse experimento quatro genótipos de milho nos sistemas de cultivo consorciado e em monocultivo. Pode-se observar que a utilização da acurácia seletiva é a melhor alternativa para avaliar a precisão experimental em experimentos em consórcio. 0 experimento em estudo apresentou acurácia entre 0,91 e 0,95 , respectivamente para massa de espigas comerciais com palha e rendimento de grãos, apresentando assim uma boa precisão experimental.
\end{abstract}

PALAVRAS-CHAVE: Zea mays; acurácia, erro experimental

\section{EVALUATION OF THE EXPERIMENTAL PRECISION OF A CORN EXPERIMENT IN A CONSORTIUM WITH BEANS FOR THE PRODUCTION OF GREEN AND DRY MAIZE}

\begin{abstract}
Corn is one of the most economically and socially important agricultural crops because it is grown for small and large producers. Small producers mostly use the consortium system in their production, so several experiments of this nature have been carried out. This type of experiment, due to its heterogeneous nature, always presents a high coefficient of variation. To verify experimental precision, many researchers are using other statistical parameters, such as the F, Tukey, accuracy test, among others. The objective of this work was to evaluate the experimental precision of a corn experiment in a consortium with beans for the production of green and dry corn. Four maize genotypes were used in the intercropping and monoculture systems. It can be observed that the use of selective accuracy is the best alternative to evaluate the experimental precision in experiments in consortium. The experiment under study presented an accuracy of between 0.91 and 0.95 , respectively for the mass of commercial ears with straw and yield of grains, thus presenting a good experimental precision.
\end{abstract}

KEYWORDS: Zea mays, accuracy, experimental error

\section{INTRODUÇÃO}

O milho é uma das espécies cultivadas que apresentam maior importância para humanidade, devido as suas diversas formas de consumo, pois desse vegetal todas as estruturas são aproveitadas, desde os grãos para alimentação humana e animal até a parte aérea para alimentação animal, cobertura de solo, produção de bioenergia dentre outras utilizações (MAPA, 2011; Silva et al, 2008) 
As principais formas de utilização do milho são em grãos secos e verde, processados ou não, de acordo com as necessidades, aptidões de cada região e nível de tecnificação do produtor, em função disso, diversas pesquisas têm sido realizadas visando aumentar a eficiência produtiva da cultura (Carvalho, 2015).

Nas pesquisas desenvolvidas para que possam ter respaldo científico e tecnológico é necessário seguir alguns requisitos pré-estabelecidos, como utilização do delineamento experimental adequado, utilizar um número amostral satisfatório, respeitar os princípios da experimentação, a repetição, a casualização e 0 controle local (Gomes, 1987).

Uma das formas de conhecer a precisão experimental da pesquisa é por meio do coeficiente de variação experimental $C V$, que é considerado de ótima precisão abaixo de 10\%, de boa precisão entre 10 e $15 \%$, de regular precisão entre 15 e $20 \%$ e aceitável entre 20 e 30\%, superando esse limite é considerado muito alto, o que compromete consideravelmente os resultados da pesquisa (Ferreira, 2006).

O coeficiente de variação é influenciado pelo ambiente em que a pesquisa é realizada, fato que pode comprometer os resultados, pois devido as características da pesquisa um CVe elevado não necessariamente reflete em uma pesquisa conduzida de maneira equivocada, pois o CVe considera-se apenas a variação residual como proporção média do experimento (Cargnelutti Filho; Storck, 2007).

Em pesquisas em que é utilizado o sistema de consorciação de culturas, normalmente o CVe é alto, pois a presença de duas ou mais culturas em uma mesma área aumenta a heterogeneidade das condições ambientais, devido a interação entre as duas espécies com 0 ambiente (Carvalho, 2015; Ferreira, 2006).

Diversos pesquisadores, buscando solucionar os problemas de mensuração e interpretação da precisão experimental passaram a utilizar diversos parâmetros estatísticos como a herdabilidade, coeficiente de determinação, teste $F$, acurácia, entre outros (Cargnelutti Filho; Storck, 2007; Resende; Duarte, 2007).

O objetivo desse trabalho foi avaliar a precisão experimental de um experimento de milho em consórcio com feijão para a produção de milho verde e seco.

\section{MATERIAL E MÉTODOS}

O experimento foi conduzido no ano de 2014 durante os meses de agosto a dezembro na área experimental do Centro de Ciências Agrárias da Universidade Federal de Alagoas (CECA/UFAL) Campus Delza Gitaí, BR 104 Norte, km 85, situado no Município de Rio Largo, Estado de Alagoas.

0 delineamento experimental utilizado foi em blocos casualizados no esquema fatorial (4x2), com três repetições. Foram avaliados nesse experimento quatro genótipos de milho, dos quais três desenvolvidos pelo Setor de Melhoramento Genético de Plantas (SMGP) do CECA/UFAL: Alagoano, Viçosense e Nordestino, e uma variedade comercial desenvolvida pela EMBRAPA, BRS 5037 (Cruzeta), em dois sistemas de plantio, monocultivo e consorciado com feijão (Phaseolus vulgaris L.), variedade IAC Alvorada.

As parcelas com milho em monocultivo tiveram 6 fileiras de plantas com 5,0 m de comprimento, espaçadas a 1,0 m entre linhas e 0,2 m entre plantas, com uma planta por cova, constituindo uma população de milho de 50.000 plantas.ha-1 $^{-1}$. As parcelas consorciadas tiveram as mesmas dimensões, porém nas entre linhas de milho tiveram duas fileiras de plantas de feijão com 5,0 m de comprimento, espaçadas a 0,4 $m$ entre linhas e $0,3 \mathrm{~m}$ entre plantas, com duas plantas por cova, constituindo uma população de feijão de 113.333 planta.ha-1.

Nas parcelas de milho em monocultivo e em consórcio, foram consideradas como área útil às quatro fileiras centrais, de modo que duas foram colhidos 0 milho verde e nas demais, milho em grãos, também foram eliminadas duas plantas de cada extremidade das fileiras.

O preparo do solo ocorreu manualmente com uso de enxadas e logo após foram abertos os sulcos com cerca de 10 centímetros de profundidade, onde foi aplicado o esterco ovino/caprino e incorporado dentro do sulco, em que foi aplica 10 ton.ha ${ }^{-1}$ para o milho e 8 ton.ha-1 ${ }^{-1}$ para o feijão.

O plantio ocorreu no dia 20 de agosto de 2014 , sendo semeadas manualmente três sementes por cova de cada cultura, ambas com profundidades de 3 a 4 centímetros, e 10 dias após foi realizado o desbaste. As fileiras de plantas ficaram no sentido leste-oeste.

O controle de plantas daninhas foi realizado com duas capinas manuais com enxada realizadas aos 
15 e 35 dias após o plantio. Para a manutenção das condições hídricas do solo e ideal desenvolvimento das culturas, foi instalado um sistema de irrigação por aspersão, com lâmina diária de $7 \mathrm{~mm}$, sendo aplicados nos veranicos durante a condução do experimento. Durante a condução do experimento os dados meteorológicos foram: Precipitação: 153,7; 135,9; 229,4 e 48,36 mm, do mês de agosto a novembro de 2015 , temperatura média nos meses de $23,55^{\circ} \mathrm{C}$, média mínima $18,77^{\circ} \mathrm{C}$, média máxima $30,07^{\circ} \mathrm{C}$ e umidade relativa do ar de $80,1 \%$.

A colheita do milho verde ( $75 \%$ de umidade) foi realizada aos 80 dias após o plantio, os grãos secos foram colhidos aos 120 dias após (secagem natural ao sol até atingir a umidade de 13\%) e para o feijão verde (63\% de umidade) aos 70 dias.

A variável avaliada foi a massa das espigas comerciais com palha para o milho verde e o rendimento de grãos para o milho seco.

A verificação da precisão experimental foi realizada por meio da acurácia seletiva (AS), média das variáveis, coeficiente de variação experimental (CVe), diferença mínima significativa pelo teste de Tukey a $5 \%$ de probabilidade, e teste $F$, esse calculados pelas fórmulas:

Acurácia seletiva:

$$
\hat{r}_{\hat{g} g}=\sqrt{1-\frac{1}{F C}}
$$

Coeficiente de variação experimental:

$$
\text { CVe }(\%)=\frac{\sqrt{\text { QMres }}}{\bar{x}} \cdot 100
$$

Teste de Tukey:

$$
\Delta(5 \%)=\mathrm{q} \frac{\mathrm{s}}{\sqrt{\mathrm{r}}}
$$

Teste F:

$$
\mathrm{F}=\frac{\mathrm{QMT}}{\mathrm{QMR}}
$$

Os parâmetros de precisão experimental foram calculados pelo aplicativo DELPAPA.

\section{RESULTADOS E DISCUSSÃO}

$\mathrm{Na}$ Tabela 1 apresentam-se valores da estatística $\mathrm{F}$ para os efeitos de tratamentos na análise da variância, relacionados ao nível de acurácia obtido ou requerido $A S=(1-1 / F) 1 / 2$. São destacados na tabela os valores de $F$ que foram obtidos nos experimentos, visando-se estimar/predizer com elevada acurácia. Observa-se, por exemplo, que para se atingir uma acurácia seletiva ideal de $90 \%(0,9)$ ou mais - correspondente a valores de coeficiente de determinação acima de $80 \%$, conforme preconizam (Steel; Torrie, 1980), para uma inferência estatística segura - os valores de $F$ para cultivares devem ser iguais ou superiores a 5,26 no qual é visto no presente trabalho. Por conseguinte, este pode ser um valor de referência para os experimentos de avaliação de precisão experimental. Tal valor independe da espécie cultivada e do caráter sob avaliação, podendo servir como padrão para avaliar experimentos dessa natureza e do caráter sob avaliação.

Tabela 1. Parâmetros de precisão em experimento de milho em consórcio com feijão.

\begin{tabular}{lccccc}
\hline Ensaios & AS & Média & CVe & D & F \\
\hline RG & 0,95 & 3,92 & 25,2 & 0,75 & 9,9 \\
MECCP & 0,91 & 10,97 & 18,0 & 0,54 & 6,4 \\
\hline
\end{tabular}

RG - Rendimento de grãos (t.ha-1); MECCP - Massa de espigas comerciais com palha (t.ha $\left.{ }^{-1}\right)$; AS - Acurácia seletiva; CVe - Coeficiente de variação experimental; D - Diferença mínima significativa pelo teste de Tukey; F - Teste F.

De acordo com essa análise, tanto a avaliação do rendimento de grãos para o milho seco, quanto para a massa de espigas comerciais com palha para o milho verde, 0 ensaio de competição das cultivares de milho em consórcio com feijão apresentaram precisão muito alta (AS $=0.91,0.95)$ superior $a \leq 0.90$. A estatística acurácia seletiva é adequada para avaliar a precisão experimental dos ensaios de competição de genótipos de milho em consórcio com feijão.
A estatística acurácia seletiva é adequada para avaliar a precisão experimental dos ensaios de competição de genótipos de milho em consórcio com feijãoe descartar ensaios apenas com base no coeficiente de variação (CV= 25.2) na qual apresentou uma acurácia seletiva $<0.90$ é uma atitude desaconselhável.

Levando em consideração o CVe esse experimento segundo a classificação de (5) seria 
aceitável por se tratar de um experimento de consórcio, porém ainda assim alguns pesquisadores não dariam credibilidade ao mesmo levando em consideração a variação residual que acarreta em um CV e elevado. Com a utilização da acurácia seletiva fica claro que o presente trabalho apresentou alta precisão experimental.

Conclui-se que a acurácia é uma alternativa para verificar a precisão experimental em pesquisas com o uso de consorciação de culturas e que o presente experimento apresentou confiabilidade quanto a precisão experimental.

\section{REFERÊNCIAS BIBLIOGRÁFICAS}

CARGNELUTTI FILHO, A.; Storck, L. Pesquisa Agropecuária Brasileira, 2007, 42, 17-24.

CARVALHO, I.D.E. Dissertação de Mestrado, Universidade Federal de Alagoas, 2015.
Ferreira, P.V. Melhoramento de plantas: princípios e perspectivas, Edufal, Maceió, 2006.

GOMES, F.P. Curso de estatística experimental, ESALQ, Piracicaba, 1987.

MAPA (Ministérios da Agricultura Pecuária e Abastecimento) - Panorama do Milho: Balanço de Oferta e Demanda. 2011.

RESENDE, M.D.V.; DUARTE, J.B. Pesquisa Agropecuária Tropical, 2007, 37, 182-194.

SILVA, E.C.; MURAOKA, T.; BUZETTI, S.; SINENCIO, C.E.; TRIVELIN, P.C.O. Revista Brasileira de Ciências do Solo, 2008, 32, 2853-286.

STEEL, R.G.D.; TORRIE, J.H. Principles and procedures of statistics, Mcgraw-Hill, New York, 1980. 